\title{
Nepali translation, cross-cultural adaptation and measurement properties of the Shoulder Pain and Disability Index (SPADI)
}

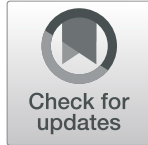

\author{
Sudarshan KC ${ }^{1}$, Saurab Sharma ${ }^{2,3^{*}} \mathbb{D}$, Karen Ginn ${ }^{1}$, Tawfiq Almadi ${ }^{1}$ and Darren Reed ${ }^{1}$
}

\begin{abstract}
Background: The Shoulder Pain and Disability Index (SPADI) is a 13-item shoulder-specific patient-reported outcome measure (PROM). The English version is easy to use and has demonstrated excellent measurement properties for both clinical and research settings. The availability of the SPADI in Nepali would facilitate shoulder research and enhance management of patients with shoulder pain in Nepal. Therefore, the purpose of this study was to translate and crossculturally adapt the SPADI into Nepali (SPADI-NP) and evaluate its measurement properties.

Methods: The translation and adaptation process followed international guidelines. Participants completed SPADI-NP on two assessments ( $N=150$ at initial and 119 at follow-up assessment). A Nepali version of the Global Rating of Change score was completed at follow-up. Assessment of measurement properties included analysis of internal consistency (Cronbach's a), minimal detectable change (MDC) with standard error of measurement (SEM), test-retest reliability (intraclass correlation coefficient; ICC), validity (factor structure, construct using Pearson's correlation with the Disability of Arm and Hand [DASH]) and responsiveness (area under the curve; AUC) with minimal important change (MIC).
\end{abstract}

Results: Minor changes were integrated in the adaptation process to improve cultural relevance such as dress items. Items were largely loaded under two factors (pain and disability), internal consistencies were good for the pain construct $(a=0.82)$ and disability $(a=0.88)$ and test-retest reliability was excellent (pain $=0.89$, disability $=0.96)$. MDC was 5.7 (out of 100) with SEM $=2.1$. Strong associations with the DASH ( $r=0.63$ pain, $r=0.81$ disability) demonstrated its construct validity. The AUC was 0.68 and MIC was 12.3 (out of 100).

Conclusion: The Nepali version of the SPADI demonstrated excellent reliability and validity. It can be used for the assessment of shoulder pain and disability in patients with shoulder pain in Nepal in both clinical practice and research.

Keywords: SPADI, Shoulder pain, Disability, Pain, Translation, Psychometrics, Clinimetrics, Outcome assessment

\section{Introduction}

Health-related patient-reported outcome measures (PROMs) are an important component of clinical assessments, providing the patients' perspective of their health status and functional capacity. PROMs can consequently direct treatment and provide valuable feedback of progress of clinical conditions. They are also increasingly used as primary outcome measures in research. For valid use in different language

\footnotetext{
*Correspondence: saurabsharma1@gmail.com

${ }^{2}$ Department of Physiotherapy, Kathmandu University School of Medical Sciences, Dhulikhel, Kavre, Nepal

${ }^{3}$ Department of Surgical Sciences, Dunedin School of Medicine, University of Otago, Dunedin, Otago, New Zealand

Full list of author information is available at the end of the article
}

groups, PROMs must not only be translated but also cross-culturally adapted, and measurement properties (validity, reliability and responsiveness) confirmed [1].

The Shoulder Pain and Disability Index (SPADI) is one of the most commonly used shoulder-specific heath status questionnaires [2] and has been described as the most responsive shoulder pain and disability tool for shoulder conditions [3]. It has also been ranked as one of the most relevant questionnaires by shoulder patients being easy to complete and the least time consuming [4]. The SPADI consists of 13 items and is divided into 2 constructs: pain (5 items) and functional disability (8 items). The SPADI was originally developed using a visual analogue scale 
(VAS) [5] but later modified to use a numerical rating scale to increase its versatility for interview or selfreporting administration [6]. The original English version has been shown to have excellent measurement properties in various shoulder conditions [2]. It has subsequently been translated and cross-culturally adapted into multiple languages (e.g. Norwegian, Turkish, Danish) with acceptable measurement properties [7]. However, it has not been translated into Nepali and there is currently no shoulder-specific PROM available in the Nepali language. Translation of an easy to use, versatile shoulder outcome measure such as the SPADI into Nepali would benefit Nepali therapists and medical practitioners in the clinical assessment of shoulder conditions and facilitate ongoing shoulder research in Nepal.

Therefore, the aims of this study were to (1) translate and cross-culturally adapt the SPADI into Nepali, (2) determine the measurement properties of the translated version and (3) compare the efficacy of administering the questionnaire by interview or self-completion.

\section{Methods and materials}

The study was completed in two phases: translation and adaptation of the English version of the SPADI as recommended by the American Association of Orthopaedic Surgeons (AAOS) Outcomes Committee [8] and measurement property testing of the Nepali version of the SPADI as per the COnsensus-based Standards for the selection of health Measurement INstruments (COSMIN) checklist [9]. The permission to translate the SPADI into Nepali was granted by the original developer. The Institutional Review Committee of Kathmandu University School of Medical Sciences, Dhulikhel, Nepal, approved the study protocol.

\section{Participants}

A sample of 150 participants was set as a target to meet the recommended number of participants to test the measurement properties of a PROM [10]. The inclusion criteria for participation were current shoulder pain, aged over 18 years and able to speak Nepali fluently. Shoulder pain was referred to as pain over the shoulder and/or antero-lateral aspect of the upper arm, which was aggravated by shoulder movements. Participants also had to test positive to one of the following clinical tests: Hawkin's impingement test, Neer's impingement test or resisted isometric manual muscle tests (external rotation and abduction). In order to capture a representative sample from both rural and urban areas of Nepal, the physiotherapy outpatient department of three hospitals (a not-for-profit community-based hospital, a general urban hospital and a large orthopaedic hospital) were used to recruit participants. The participants were provided with verbal information about the study and a written participant information statement in Nepali, which was read to illiterate participants. Literate participants signed their informed consent, and illiterate participants' consent was gained verbally and signed by a witness.

\section{Instruments \\ Shoulder Pain and Disability Index (SPADI)}

The 13-item tool (5 pain, 8 disability) SPADI is scored on an ordinal scale from 0 (no pain/no difficulty) to 10 (worst pain imaginable) with higher scores indicating greater pain and/or disability. To obtain a score out of 100 , the total scores of all items are summed and divided by the highest possible score (130) and then multiplied by 100 . If more than two items are left blank, the scoring is considered invalid [5].

\section{Nepali version of the Global Rating of Change (GROC-NP)}

The GROC assesses the self-perceived change of the participant's health condition. It is commonly used in research and is the most common tool used to dichotomise shoulder pain sufferers into stable and changed groups [11]. The Nepali version of the GROC is based on a 7-point scale, which has been translated into Nepali [12] and has been used as an external anchor to dichotomise improved and stable groups previously [12-14]. The middle score of ' 4 ' in the scale indicates no change in symptoms (stable), scores higher than 4 indicate progressive increments of improvement (slight, moderate and large) and a score lower than 4 indicates worsening symptoms (slight, moderate and large). A change of 1 point is considered important change [12, 15].

\section{The Nepali version of Disability of Arm, Shoulder and Hand (DASH-NP)}

The DASH is a 30 -item scale measuring patient-reported pain and functional limitations. The Nepali version of the DASH has been cross-culturally translated and adapted and shown to be valid, reliable and responsive [16]. Each item is scored on a 5-point Likert scale giving a total score calculated out of 100 , with higher scores indicating greater pain and disability. If more than three items are left blank, it is considered invalid.

\section{Phase I-Translation procedures and cross-cultural adaptation}

Translation and cross-cultural adaptation were completed in five steps.

- Three forward translations of the original SPADI were independently created by a health professional, a non-medical person and a professional translator registered with and 
accredited by the National Accreditation Authority for Translators and Interpreters Ltd., Australia. All were bilingual, born in Nepal and native Nepali speakers. A written report was submitted by each translator outlining difficulties in the translation process.

- The three forward translations were then synthesised into a single version by the study coordinator (SKC) and two university academics (DR and SS), all bilingual and native English or Nepali speakers. Discrepancies in the translations were discussed and a consensus reached for backtranslation.

- Two bilingual, native English-speaking translators, naive to the study aims, independently backtranslated the synthesised version of the SPADI and submitted a written report suggesting any difficult or unclear phrases.

- An expert committee, comprising all translators, the principal investigator (SKC) and two university academics (DR, SS) reviewed the translated versions and discussed discrepancies/ difficulties highlighted during the translation process. Consensus was reached within the expert committee, and a pre-final Nepali version of the SPADI (SPADI-NP) was produced.

The first five study participants completed the prefinal version of SPADI-NP and were interviewed using prepared questions to assess the layout, the wording of phrases and the ease of understanding of the questionnaire (comprehensibility). Majority consensus was used to accept phrases where more than one viable option was proposed. The data from these five participants were not retained for further analysis. This process led to the final version of the SPADI-NP.

\section{Procedures}

At the initial assessment, participants were provided with an information sheet, consent form, SPADI-NP and a validated Nepali version of the DASH-NP. The SPADI-NP was administered on a second occasion 23 weeks post-initial assessment along with the GROCNP. Literate participants completed the SPADI-NP as a self-reported measure. Illiterate participants were interviewed by the physiotherapist who read the questionnaire to participants asking them to verbally select the most appropriate score without any prompting. If participants were unable to return to the hospital for follow-up due to remote living, a phone interview was used to collect follow-up data. All interviews and testing were performed by physiotherapists trained in the administration of the SPADI and data management procedures.

\section{Phase II-measurement property testing}

Data was entered into an excel spreadsheet and later transferred to SPSS version 24 for statistical analyses.

\section{Factor analysis}

Suitability of data for factor analysis was assessed using correlations between the scale items with a threshold set at 0.40 [17], a Kaiser-Meyer-Okin (KMO) sample adequacy index requirement $>0.90$ and a significant Bartlett's sphericity test. A principal component analysis with varimax rotation was performed to examine the component structure of the 13-item SPADI-NP. Factors were retained if they had eigenvalues $>1$. All eigenvalues were plotted on a Cattell's Scree plot [18]. Items with loadings above 0.40 were assumed to load on a given factor.

\section{Internal consistency}

Internal consistency was analysed within the two constructs of pain and disability and as a total using Cronbach's alpha $(\alpha)$ [19]. Scores between 0.50 and 0.69 were considered poor, 0.70 and 0.79 acceptable, 0.80 and 0.89 good and $>0.90$ excellent [20].

\section{Test-retest reliability}

Test-retest reliability was determined using intraclass correlation coefficient $\left(\mathrm{ICC}_{2,1}\right)$ between the initial and follow-up SPADI-NP scores of the participants in the stable group. Scores of $<0.40$ were considered poor correlation, $0.40-0.59$ fair, $0.60-0.74$ good and $>0.75$ excellent [19].

\section{Measurement error}

Minimal detectable change (MDC) was calculated using the formula MDC $=z \times \sqrt{2} \times \mathrm{SEM}$, where $z=1.96$ ( $z$ score for estimating a $95 \%$ confidence interval), $\sqrt{2}$ indicates the two SPADI-NP measurements and SEM is the standard error of measurement calculated using the formula; $\mathrm{SEM}=\mathrm{SD}(1-\mathrm{ICC})^{1 / 2}$, where SD is the standard deviation for the mean change of SPADI-NP score from baseline to follow-up measurement and ICC is the intraclass correlation coefficient of the stable group. 


\section{Construct validity}

Correlation between the pain items and disability items of the SPADI-NP and DASH-NP and the total SPADI$\mathrm{NP}$ and the GROC-NP scores were calculated using Pearson's correlation. We hypothesised that there would be a moderate to high positive correlation between the SPADI-NP and DASH-NP items and a moderate negative correlation with the GROC-NP. Coefficients $<0.35$ represented low, 0.36-0.67 moderate, $0.68-0.89$ high and $\geq 0.90$ very high correlations [21].

Independent $t$ tests were performed to compare the mean scores of participants completing the SPADI by self-marking with participants who were interviewed. Those completing the questionnaire by interview were further sub-grouped at the follow-up assessment, and an independent $t$ test was used to compare those interviewed by phone with those interviewed at the hospital. Our a priori hypothesis was that there would be no difference in mean score between self-marking and any of the interview categories. The SPADI-NP would be considered to have acceptable construct validity if a minimum of four out of these five (i.e. $80 \%$ ) a priori hypotheses were met [22].

\section{Responsiveness}

Receiver operating characteristic (ROC) curves were plotted. The area under the curve (AUC) was used to measure the SPADI's ability to distinguish between these two groups and provide an indication of responsiveness [11]. An AUC >0.70 was considered acceptable [22]. The minimal important change (MIC) was determined from the ROC curves.

\section{Results}

\section{Participants}

A description of the participant demographics is shown in Table 1. One hundred and fifty-six participants $(75 \mathrm{M}, 81 \mathrm{~F} ; 47.7 \pm 13.5$ years $)$ were recruited from the three physiotherapy outpatient departments. After exclusion of invalid questionnaires with $>2$ items left blank (six at initial assessment and two at follow-up, total 3\%), 150 completed SPADI-NP questionnaires were available from the initial assessment (66 by interview, 84 by self-report) and at follow-up assessment 119 (79\%; 84 by interview over the phone, 25 by interview at a hospital, 10 by selfreporting). Thirty-one participants were categorised as "stable" with a GROC-NP score of 4 (15 of these completed both assessments by interview, 15 by selfreport then interview and 1 by self-report at both assessments). Eighty-eight participants were categorised
Table 1 Demographic description of participants

\begin{tabular}{|c|c|c|}
\hline Items & $n(\%)$ & Mean \pm SD \\
\hline \multicolumn{3}{|l|}{ Gender } \\
\hline Male & 75 (48\%) & \\
\hline Females & $81(52 \%)$ & \\
\hline Age & & $47.7 \pm 13.5$ years \\
\hline \multicolumn{3}{|l|}{ Education } \\
\hline No education & $70(45)$ & \\
\hline Primary & $58(37)$ & \\
\hline Secondary & $14(9)$ & \\
\hline Bachelor and above & $14(9)$ & \\
\hline \multicolumn{3}{|l|}{ Occupation } \\
\hline Business & $27(17)$ & \\
\hline Office work & $17(11)$ & \\
\hline Agriculture & $11(7)$ & \\
\hline Students & $6(4)$ & \\
\hline Others (inc. house work) & $95(61)$ & \\
\hline \multicolumn{3}{|l|}{ Ethnicity } \\
\hline Brahmin & $43(27)$ & \\
\hline Newar & $26(17)$ & \\
\hline Chettri & $20(13)$ & \\
\hline Others & $67(43)$ & \\
\hline \multicolumn{3}{|l|}{ Religion } \\
\hline Hindu & $93(60)$ & \\
\hline Buddhist & $34(22)$ & \\
\hline Others & $29(18)$ & \\
\hline
\end{tabular}

as "improved" with a GROC-NP score of 5, 6 or 7 . No participant reported a GROC-NP score $<4$ or worsening.

\section{Translation and cross-cultural adaptation}

The following three modifications were made to the wording of the SPADI-NP during the translation and cross-cultural adaptation process. ' 10 pounds' was changed to ' $5 \mathrm{~kg}$ ' as the metric system is used in Nepal; 'pants' was changed to 'pants or suruwal' as suruwal are the traditional pants both worn by both males and females; and 'jumper' changed to 'sweater' as 'sweater' is commonly worn by both sexes. The pilot testing revealed no difficulty with the understanding (comprehensibility) of all 13 items of the SPADI-NP. Two rural participants commented that they had trouble relating the numerical score to their pain and disability levels as this is an uncommon concept in remote Nepal. The final version of SPADI is located in the Appendix. 
Table 2 Principal component factor analysis with varimax rotation for individual items

\begin{tabular}{|c|c|c|c|c|}
\hline \multirow[b]{2}{*}{ Items } & \multirow[b]{2}{*}{ Nepali } & \multirow[b]{2}{*}{ English } & \multicolumn{2}{|c|}{ Factor loading } \\
\hline & & & 1 & 2 \\
\hline & दुखाई: & Pain: & & \\
\hline 1. & एकदमै नराम्रो हुँदा & (at its worst)? & .037 & .759 \\
\hline 2. & जब दुखेको भागतिर पल्टिँदा & (when lying on the involved side)? & .102 & .869 \\
\hline 3. & अग्लो स्थानमा भएको सामान छुँन खोज्दा & (reaching for something on a high shelf)? & .524 & .613 \\
\hline 4. & आफ्नो गर्धनमा छुँदा & (touching the back of your neck)? & .504 & .448 \\
\hline 5. & दुखेको हातले धकेल्दा & (pushing with the involved arm)? & .465 & .650 \\
\hline & असक्षमता: & Disability: & & \\
\hline 6. & कपाल नुहाऊँदा & (washing your hair)? & .794 & .180 \\
\hline 7. & ढाड नुहाऊँदा & (washing your back)? & .694 & .280 \\
\hline 8. & टाँख नभएको स्वीटर वा भित्रि लुगा लगाउँदा & (putting on an undershirt or pullover sweater)? & .804 & .194 \\
\hline 9. & तलसम्म टाँख भएको स्वीटर लगाउँदा & (putting on a shirt that buttons down the front)? & .727 & .043 \\
\hline 10. & पाईन्ट/सुरुवाल लगाऊँदा & (putting on your pants)? & .591 & .102 \\
\hline 11. & अग्लो स्थानमा कुनै सामान राख्दा & (placing an object on a high shelf)? & .657 & .386 \\
\hline 12. & ५ किलोको सामान बोक्दा & (carrying a heavy object of $5 \mathrm{~kg}$ )? & .556 & .522 \\
\hline 13. & आफ्नो पछाडिको खल्ती/गोजीबाट केही झिक्दा & (removing something from you back pocket)? & .650 & .258 \\
\hline
\end{tabular}

Extraction Method: Principal Component Analysis. Rotation Method: Varimax with Kaiser Normalisation. Rotation converged in 3 iterations

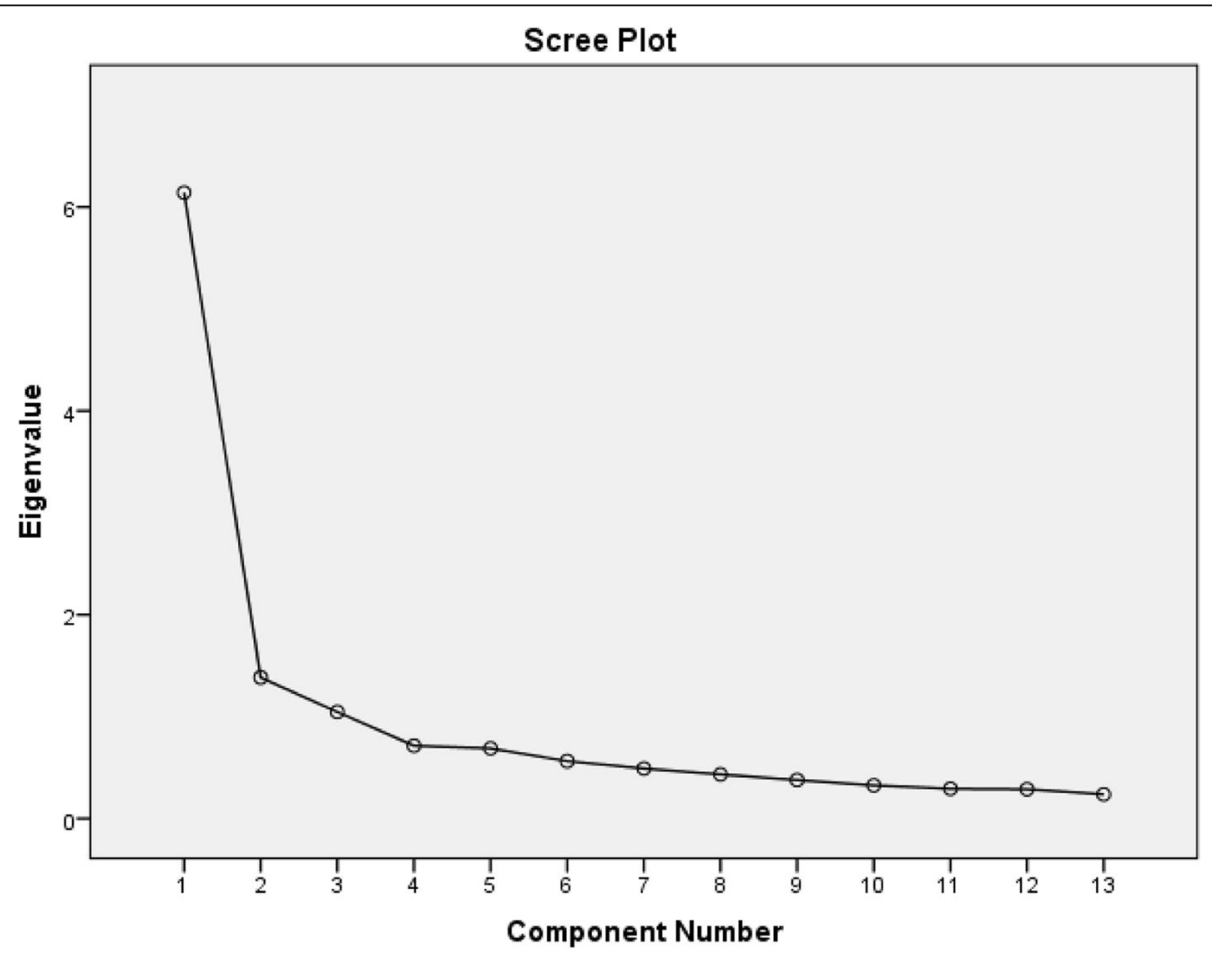

Fig. 1 The Scree plot of items of SPADI-NP (components with high eigenvalues, > 1.0) 
Table 3 Reliability and validity measures of the SPADI-NP

\begin{tabular}{llll}
\hline Measurement properties & SPADI_pain & SPADI_disability & Total SPADI-NP \\
\hline Internal consistency (Cronbach's a) & 0.82 & 0.88 & 0.90 \\
Test-retest reliability ICC $(95 \% \mathrm{Cl})$ & $0.89(0.80-0.95)$ & $0.96(0.92-0.98)$ & $0.95(0.90-0.97)$ \\
MDC & & 5.7 (out of 100) \\
SEM & & & 2.1 (out of 100) \\
Construct validity & $r=0.63^{*}$ & & $r=0.81^{*}$ \\
$\quad$ DASH-NP_pain & & & $r=-0.41^{*}$ \\
DASH-NP_disability & & & \\
GROC-NP & & & \\
\hline
\end{tabular}

Cl confidence interval, DASH-NP Nepali Disability of Arm, Shoulder and Hand score, GROC-NP Nepali Global Rating of Change, ICC intraclass correlation coefficient, MDC minimal detectable change, SEM standard error of measurement, SPADI-NP Nepali Shoulder Pain and Disability Index

*Significance $p<0.001$

\section{Measurement properties testing}

Factor analysis-data was determined to be suitable for factor analysis with many item correlation coefficients above the threshold of 0.40, a KMO sample adequacy index $>0.90$ and a significant Bartlett's sphericity test. Principal component factor analysis with varimax rotation produced loading of items in the two factors of pain and disability (Table 2) with a few items highly loading in both factors (item 3-reaching for something on a high shelf?, item 4-touching the back of your neck?, item 5-pushing with the involved arm? Item 12-carrying a heavy object of $5 \mathrm{~kg}$ ?). The Scree plot (Fig. 1) shows a break after the second component, indicating two components being retained for the varimax rotation.

Internal consistency (Cronbach $\alpha$ ) and test-retest reliability (ICC) results are shown in Table 3 and revealed acceptable values for both internal consistency and testretest reliability.

Construct validity analysis results are also included in Table 3 and confirm the five a priori hypotheses of:

- Moderate positive correlation between SPADI-NP and DASH-NP pain items $(r=0.63)$

- High positive correlation between the SPADINP and DASH-NP disability items $(r=0.81)$

- Moderate negative correlation between the mean change of the SPADI-NP scores and GROC-NP scores $(r=-0.41)$

- Similar mean scores for participants completing SPADI-NP by self-report or interview $(45.2 \pm 23.8$ and $46.1 \pm 24.3, p=0.82$ )

- Similar mean scores for participants completing SPADI-NP by face-to-face interviews at a hospital or over the telephone $(45.6 \pm 23.8$ and $48.0 \pm 24.4, p=$ 0.67).

\section{Responsiveness}

The ROC curves of the stable group versus the improved group and individual analysis between the stable group and small, medium and large improver groups are shown in Fig. 2. Table 4 includes the AUC, MIC with sensitivity and specificity analysis between the stable and improved groups. All AUC values were significant and within acceptable proximity to the 0.70 cut-off.

\section{Discussion}

The SPADI was successfully translated and crossculturally adapted into Nepali using the recommended international guidelines [8]. The excellent comprehensibility and ease of completion of the Nepali translated version of the SPADI questionnaire were reinforced by the feedback from the participants included in the pre-testing phase of this study and reflect the appraisal of the original English version in this regard [4]. The minor adaptions such as changing of the measurement units to metric and words or phrases such as dress items to commonly used equivalent Nepali terms were reported by participants to contribute to the comprehensibility of the SPADI-NP.

The SPADI-NP also demonstrated excellent validity and reliability and acceptable responsiveness for Nepali participants with shoulder pain. The factor analysis in the current study suggested the items of the SPADI-NP were loaded under two factors and largely followed the structure confirmed in the original English version of pain and disability [23, 24]. However, three pain items (item 3-reaching for something on a high shelf?, item 4-touching the back of your neck?, item 5-pushing with the involved arm?) and a disability item (item 12- 


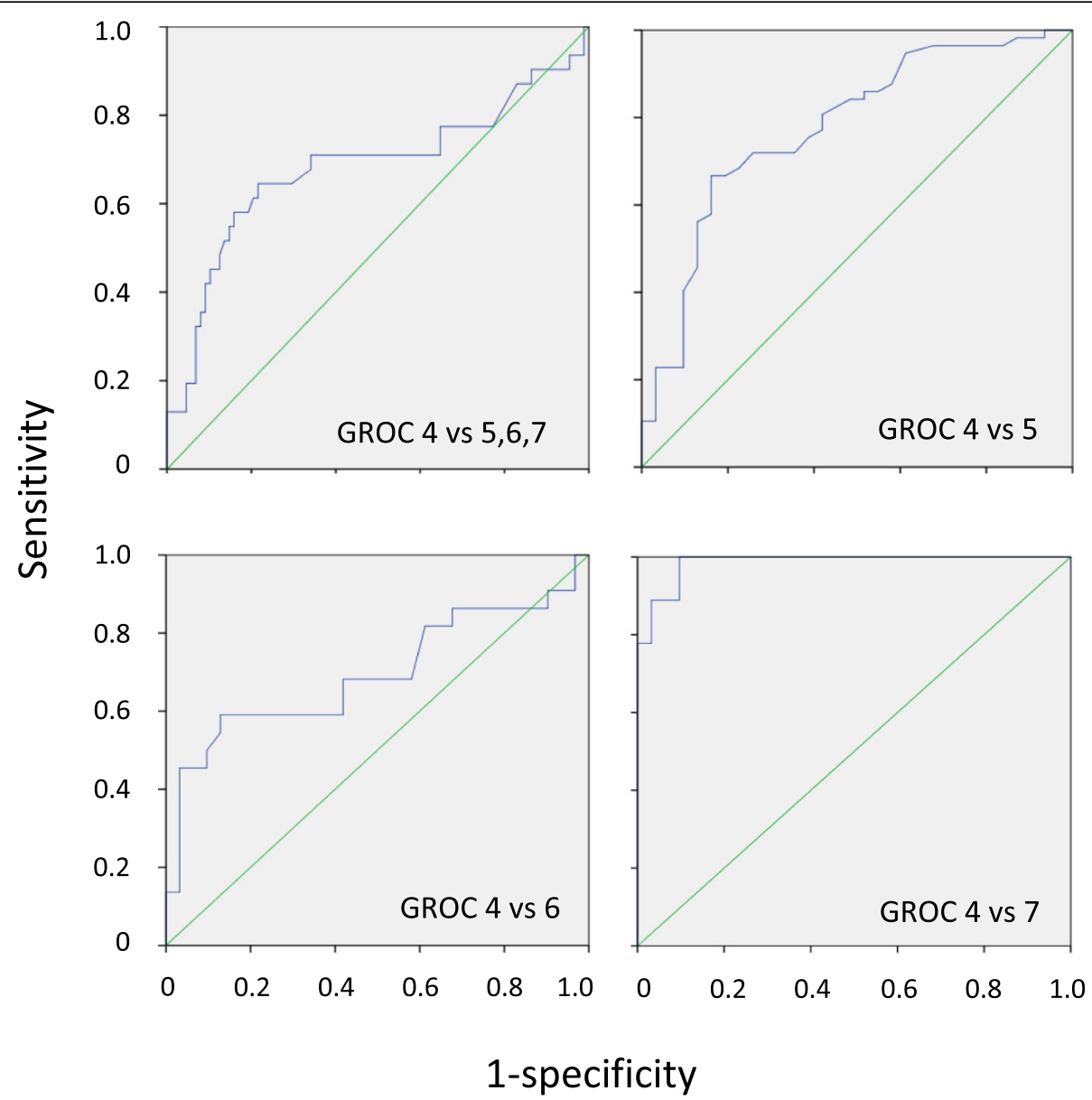

Fig. 2 Receiver operating characteristic curves between the stable and improved groups

carrying a heavy object of $5 \mathrm{~kg}$ ?) were loaded in both factors, and it does suggest that the differentiation between the two factors may be difficult in some circumstances. This may be due to individuals identifying pain as the limiting factor in task completion and making it not possible to separate pain and functional limitation/disability. This is the likely reason why previous studies have reported more of a unidimensional structure for the SPADI, especially where the pain construct is very high in conditions such as in adhesive capsulitis $[25,26]$. A recent large randomised control trial and a multicentre cohort study have provided further evidence of a two-factor structure for the SPADI, but even these studies suggest that the two factors of pain and disability are not well delineated with some items cross-loading [27, 28] and misfit of the disability items when the Rasch model is used [28].

Table 4 Area under the curve (AUC) and minimum important change (MIC) with sensitivity and specificity

\begin{tabular}{|c|c|c|c|c|c|c|c|}
\hline \multirow{2}{*}{$\begin{array}{l}\text { Stable group } \\
\text { GROC } 4(n=31) \text { vs }\end{array}$} & \multirow{2}{*}{$\begin{array}{l}\text { Improved groups } \\
\text { GROC 5, 6, } 7(n=88)\end{array}$} & \multirow{2}{*}{$\begin{array}{l}\mathrm{AUC} \\
0.68^{*}\end{array}$} & \multicolumn{2}{|c|}{$95 \% \mathrm{Cl}$} & \multirow{2}{*}{$\begin{array}{l}\text { MIC } \\
12.30\end{array}$} & \multirow{2}{*}{$\begin{array}{l}\text { Sensitivity } \\
0.65\end{array}$} & \multirow{2}{*}{$\frac{\text { Specificity }}{0.78}$} \\
\hline & & & 0.55 & 0.81 & & & \\
\hline & GROC $5(n=57)$ & $0.77^{*}$ & 0.67 & 0.88 & 6.5 & 0.67 & 0.84 \\
\hline & GROC $6(n=22)$ & $0.69 *$ & 0.54 & 0.85 & 8.5 & 0.59 & 0.87 \\
\hline & GROC $7(n=9)$ & $0.98^{*}$ & 0.96 & 0.99 & 11.15 & 0.99 & 0.99 \\
\hline
\end{tabular}


The internal consistency calculations in this study were based on the two-factor structure and demonstrated good results. The subscales and total SPADINP results are similar to the original English version and other translated versions [3, 5, 7], indicating the items that measure the same construct (i.e. pain or disability) produce similar scores and therefore are providing a reliable measure for that construct. The SPADI-NP also maintains its reliability between administration mode (interview and self-report) with excellent ICC scores for the two constructs and the overall test. However, as there are some inconsistent results of factor analysis reported in the literature, the subscale analyses of internal consistency and test-retest reliability needs to be interpreted cautiously.

The validity of the SPADI-NP was supported by confirmation of the a priori hypotheses with high positive correlation of the disability items and a moderate positive correlation between the pain items of the SPADI-NP and DASH-NP. This further suggests that the SPADI-NP is able to measure the constructs that it is intended to measure, i.e. pain and disability. Interestingly, the strength of correlation between the disability items is higher than pain. This may be the result of the higher number of disability items in the DASH-NP, giving a more comprehensive analysis, or alternatively, it could again reflect the difficulty of distinguishing pain from functional activities. The numerical scale used in the SPADI (in contrast to the DASH worded scale) was also flagged in the pretesting as a possible problem for rural participants. However, these results seem to confirm that the translated SPADI performed well for all participants.

Responsiveness as measured by the area under the curve of the ROC was shown to be significant and within acceptable proximity to the proposed cut-off of 0.70 for all comparisons between the stable and improved groups. Although this value was lower than the original SPADI (AUC 0.87) [4], it still indicates that the SPADI-NP is able to distinguish between stable and improved participants. An MIC value of 12.3 (out of 100) for the SPADI-NP was also within the range $(8-13.2)$ reported for the original English version [2], but most importantly, in the current study, the MIC was larger than the MDC and therefore represents a true minimal change value and supports the validity of the instrument.

Results of the current study showed no significant difference between the mean scores of participants completing the SPADI-NP by self-report or interview method and between face-to-face interviews at a hospital or over the phone. This evidence supports the a priori hypothesis that administration of the SPADI-
NP by self-report, phone interview and face-to-face interview are all appropriate methods of administration without compromising its validity. In addition to the rigorous cross-cultural adaption process, the COSMIN checklist recommends studies should provide some form of analysis to demonstrate representativeness of the translated PROM in the new cultural setting. This can include different analyses between groups of individuals based on ethnicity, gender, socioeconomic background, education levels etc. In the current study, we chose to compare the efficacy of administering the questionnaire by interview or selfcompletion. This was to validate the versatility of the SPADI-NP in the Nepali culture where although it is improving, poor education levels and low literacy rates remain an issue. An additional problem in Nepal is the remoteness of living and difficulty of individuals to attend follow-up appointments. Therefore, for a questionnaire to be inclusive and useful to a wide range of individuals in Nepal, it is imperative that it is able to be administered by interview (in person or over the phone) or self-reporting. The SPADI-NP meets this important criterion and increases its versatility for both rural and urban Nepali populations.

The strengths of this study were the careful translation process undertaken, diverse cohort and the thorough statistical analysis adopted from the latest COSMIN recommendations for the assessment of PROMs [9]. The use of the GROC scale as an indicator of 'overall improvement' instead of improvement in pain and/or disability may be considered a limitation of this study and could explain the lower than expected responsiveness value in this sample. Ideally, to consider it as a criterion, both the measures should assess the same construct (i.e. pain and disability). However, using GROC to assess the overall improvement is a common practice $[11,13,14]$ and is recommended by the COSMIN guidelines to dichotomise participants into stable and improved groups $[9,22]$.

\section{Conclusion}

The Nepali version of the SPADI demonstrated excellent comprehensibility, reliability, validity and acceptable responsiveness. It also proved its versatility in the method of administration by both self-report and interview (phone and face-to-face) in a wide range of Nepali shoulder pain participants. Therefore, the SPADI-NP would be recommended to assess individuals in Nepal with shoulder pain and disability in both clinical practice and research settings. 


\section{Appendix}

\section{काँध दुखाई र असक्षमता सुचक (SPADI-NP)}

गत हप्ताको काँधको समस्यालाई दर्शाउनो सबैभन्दा उचित अंकमा कृपया चिन्ह लगाउनुहोस् ।

\section{दुखाई मापक}

तपाईंको दुखाई (को मात्रा) कति छ ?

तपाईंको दुखाईलाई सबैभन्दा राम्रो व्याख्या गर्ने अंकमा गोलो लगाउनुहोस् जहाँ ० = "दुखाई छैन"

र २० = "सहनै नसक्ने दुखाई" हो।

\begin{tabular}{|c|c|c|c|c|c|c|c|c|c|c|c|}
\hline एकदमै नराम्रो हुँदा ? & 0 & $?$ & २ & ३ & $\gamma$ & 4 & $\xi$ & $७$ & $\iota$ & $\rho$ & १० \\
\hline जब दुखेको भागतिर पल्टिँदा ? & 0 & $?$ & २ & ३ & $\gamma$ & $\varphi$ & $\xi$ & $७$ & $८$ & $\rho$ & १० \\
\hline अग्लो स्थानमा भएको सामान छुँन खोज्दा ? & $\circ$ & $?$ & २ & ३ & $\gamma$ & 4 & $\xi$ & $\vartheta$ & $८$ & $\rho$ & १० \\
\hline आफ्नो गर्धनमा छुँदा ? & $\circ$ & $?$ & २ & ३ & $\gamma$ & 4 & $\xi$ & $७$ & $\iota$ & $\rho$ & १० \\
\hline दुखेको हातले धकेल्दा ? & 0 & $?$ & २ & ३ & $\gamma$ & $\varphi$ & $\xi$ & $७$ & $\iota$ & $\rho$ & १० \\
\hline
\end{tabular}

\section{असक्षमता मापक}

\section{तपाईंलाई कत्तिको गाह्रो हुन्छ ?}

तपाईंको अनुभवलाई सबैभन्दा राम्रो व्याख्या गर्ने अंकमा गोलो लगाउनुहोस् जहाँ ० = "गाह्रो छैन" र $१^{\circ}=$ "यति धैरै गाह्रो कि सहयोग चाहिन्छ" हो।

\begin{tabular}{|c|c|c|c|c|c|c|c|c|c|c|c|}
\hline कपाल नुहाउँदा ? & $\circ$ & ? & २ & ३ & 8 & 4 & $\xi$ & $७$ & $\iota$ & $\rho$ & २० \\
\hline ढाड नुहाउँदा ? & $\circ$ & $?$ & २ & ३ & 8 & 4 & $\xi$ & $७$ & $\iota$ & $\rho$ & २० \\
\hline टाँख नभएको स्वीटर वा भित्रि लुगा लगाउँदा ? & $\circ$ & $?$ & २ & ३ & $\gamma$ & 4 & $\xi$ & $७$ & $\iota$ & $\rho$ & १० \\
\hline तलसम्म टाँख भएको स्वीटर लगाउँदा ? & o & $?$ & २ & ३ & 8 & 4 & $\xi$ & $७$ & $\iota$ & $\rho$ & २० \\
\hline पाईन्ट/सुरुवाल लगाउँदा ? & o & $?$ & २ & ३ & 8 & 4 & $\xi$ & $७$ & $\iota$ & $\rho$ & २० \\
\hline अग्लो स्थानमा कुनै सामान राख्दा ? & $\circ$ & $?$ & २ & ३ & 8 & 4 & $\xi$ & $७$ & $\iota$ & $\rho$ & १० \\
\hline ५ किलोको सामान बोक्दा ? & $\circ$ & $?$ & २ & ३ & 8 & 4 & $\xi$ & $७$ & $\iota$ & $\rho$ & २० \\
\hline आफ्नो पछाडिको खल्ती/गोजीबाट केही झिक्दा ? & $\circ$ & $?$ & २ & ३ & 8 & 4 & $\xi$ & $७$ & 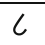 & $\rho$ & १० \\
\hline
\end{tabular}

\section{Abbreviations}

AAOS: American Association of Orthopaedic Surgeon; AUC: Area under the curve; COSMIN: COnsensus-based Standards for the selection of health Measurement INstruments; DASH: Disability of Arm, Shoulder and Hand; GROC: Global Rating of Change; ICC: Interclass coefficient correlation; KMO: Kaiser-Meyer-Okin; MDC: Minimal detectable change; MIC: Minimal importance change; PROM: Patient-reported outcome measure; ROC: Receivers operating curve; SD: Standard deviation; SEM: Standard error of measure; SPADI: Shoulder Pain and Disability Index; VAS: Visual analogue scale

\section{Acknowledgements}

We wish to thank Hari Subedi for his assistance in data collection and the Department of Physiotherapy at Dhulikhel Hospital, Nepal Orthopaedic Hospital and Medicare Hospital for facilitating this project.

\section{Authors' contributions}

The study was initiated and designed by SKC, DR, and SS. TA conducted the statistical analysis. The manuscript was drafted by SKC and supervised by DR and KG. All authors read, contributed and approved the final manuscript. 


\section{Funding}

No financial support was received related to this manuscript.

\section{Availability of data and materials}

The datasets used and/or analysed during the current study are available from the corresponding author on reasonable request.

\section{Ethics approval and consent to participate}

The study protocol was approved by the Institutional Review Committee of Kathmandu University School of Medical Sciences (ref. no. 63/16). All the participants provided consent to participate in the study.

\section{Consent for publication}

All authors provide consent for publication.

\section{Competing interests}

The authors declare that they have no competing interests.

\section{Author details}

'Discipline of Anatomy and Histology, Faculty of Medicine and Health, University of Sydney, Sydney, Australia. ${ }^{2}$ Department of Physiotherapy, Kathmandu University School of Medical Sciences, Dhulikhel, Kavre, Nepal. ${ }^{3}$ Department of Surgical Sciences, Dunedin School of Medicine, University of Otago, Dunedin, Otago, New Zealand.

Received: 29 March 2019 Accepted: 18 July 2019

Published online: 30 August 2019

\section{References}

1. de Vet HCW, Terwee CB, Mokkink LB, Knol DL. Measurement in medicine. Cambridge: Cambridge University Press; 2011.

2. Roy JS, MacDermid JC, Woodhouse LJ. Measuring shoulder function: a systematic review of four questionnaires. Arthritis Rheum. 2009;61(5):623-32.

3. Angst F, Schwyzer HK, Aeschlimann A, Simmen BR, Goldhahn J. Measures of adult shoulder function: Disabilities of the Arm, Shoulder, and Hand Questionnaire (DASH) and its short version (QuickDASH), Shoulder Pain and Disability Index (SPADI), American Shoulder and Elbow Surgeons (ASES) Society standardized shoulder assessment form, Constant (Murley) Score (CS), Simple Shoulder Test (SST), Oxford Shoulder Score (OSS), Shoulder Disability Questionnaire (SDQ), and Western Ontario Shoulder Instability Index (WOSI). Arthritis Care Res (Hoboken). 2011;63(Suppl 11):S174-88.

4. Paul A, Lewis M, Shadforth M, Croft P, Van Der Windt D, Hay E. A comparison of four shoulder-specific questionnaires in primary care. Ann Rheum Dis. 2004:63(10):1293-9.

5. Roach KE, Budiman-Mak E, Songsiridej N, Lertratanakul Y. Development of a shoulder pain and disability index. Arthritis Care Res (Hoboken). 1991:4(4):143-9.

6. Williams JW Jr, Holleman DR Jr, Simel DL. Measuring shoulder function with the Shoulder Pain and Disability Index. J Rheumatol. 1995:22(4):727-32.

7. Thoomes-de Graaf M, Scholten-Peeters GGM, Schellingerhout JM, Bourne AM, Buchbinder R, Koehorst M, Terwee CB, Verhagen AP. Evaluation of measurement properties of self-administered PROMs aimed at patients with non-specific shoulder pain and "activity limitations": a systematic review. Qual Life Res. 2016:25(9):2141-60

8. Beaton DE, Bombardier C, Guillemin F, Ferraz MB. Guidelines for the process of cross-cultural adaptation of self-report measures. Spine. 2000;25(24):3186-91.

9. Mokkink LB, Terwee CB, Patrick DL, Alonso J, Stratford PW, Knol DL, Bouter LM, de Vet HC. The COSMIN checklist for assessing the methodological quality of studies on measurement properties of health status measurement instruments: an international Delphi study. Qual Life Res. 2010;19(4):539-49.

10. Terwee $C B$, Bot SD, de Boer MR, van der Windt DA, Knol DL, Dekker J, Bouter LM, de Vet HC. Quality criteria were proposed for measurement properties of health status questionnaires. J Clin Epidemiol. 2007:60(1):34-42.

11. Chester R, Jerosch-Herold C, Lewis J, Shepstone L. The SPADI and QuickDASH are similarly responsive in patients undergoing physical therapy for shoulder pain. J Orthop Sports Phys Ther. 2017;47(8):538-47.

12. Sharma S, Palanchoke J, Reed D, Haxby Abbott J. Translation, cross-cultural adaptation and psychometric properties of the Nepali versions of numerical pain rating scale and global rating of change. Health Qual Life Outcomes. 2017;15(1):236
13. Sharma S, Pathak A, Abbott JH, Jensen MP. Measurement properties of the Nepali version of the Connor Davidson resilience scales in individuals with chronic pain. Health Qual Life Outcomes. 2018;16(1):56.

14. Sharma S, Palanchoke J, Abbott JH. Cross-cultural adaptation and validation of the Nepali translation of the patient-specific functional scale. J Orthop Sports Phys Ther. 2018;48(8):659-64.

15. Kamper SJ, Maher CG, Mackay G. Global rating of change scales: a review of strengths and weaknesses and considerations for design. J Man Manip Ther. 2009:17(3):163-70.

16. KC S, Sharma S, Ginn K, Almadi T, Subedi H, Reed D. Cross-cultural adaptation and measurement properties of the Nepali version of the DASH (disability of arm, shoulder and hand) in patients with shoulder pain. Health Qual Life Outcomes. 2019;17(1):51.

17. Tabachnick BG. FLS: using multivariate statistics, vol. 2001. 4th ed. Needham heights, Mass: Allyn and Bacon; 2001.

18. Cattell R. The Scree test for the number of factors. Multivariate Behav Res. 1966;1(2):245-76.

19. Cicchetti DV. Guidelines, criteria, and rules of thumb for evaluating normed and standardized assessment instruments in psychology. Psychol Assess. 1994:6(4):284-90.

20. Cronbach LJ. Coefficient alpha and the internal structure of tests. Psychometrika. 1951;16(3):297-334.

21. Taylor R. Interpretation of the correlation coefficient: a basic review. J Diagn Med Sonography. 1990;6(1):35-9.

22. Prinsen C, Mokkink L, Bouter L, Alonso J, Patrick D, de Vet H, Terwee C. COSMIN guideline for systematic reviews of patient-reported outcome measures. Qual Life Res. 2018;27(5):1147-57.

23. MacDermid JC, Solomon P, Prkachin K. The Shoulder Pain and Disability Index demonstrates factor, construct and longitudinal validity. BMC Musculoskelet Disord. 2006;7:12.

24. Hill CL, Lester S, Taylor AW, Shanahan ME, Gill TK. Factor structure and validity of the shoulder pain and disability index in a population-based study of people with shoulder symptoms. BMC Musculoskelet Disord. 2011:12(1):8.

25. Tveita EK, Sandvik L, Ekeberg OM, Juel NG, Bautz-Holter E. Factor structure of the Shoulder Pain and Disability Index in patients with adhesive capsulitis. BMC Musculoskelet Disord. 2008;9:103.

26. Roddey TS, Olson SL, Cook KF, Gartsman GM, Hanten W. Comparison of the University of California-Los Angeles shoulder scale and the simple shoulder test with the shoulder pain and disability index: single-administration reliability and validity. Phys Ther. 2000;80(8):759-68.

27. Dawson J, Harris KK, Doll H, Fitzpatrick R, Carr A. A comparison of the Oxford shoulder score and shoulder pain and disability index: factor structure in the context of a large randomized controlled trial. Patient Relat Outcome Meas. 2016:7:195.

28. Jerosch-Herold C, Chester R, Shepstone L, Vincent JI, MacDermid JC. An evaluation of the structural validity of the shoulder pain and disability index (SPADI) using the Rasch model. Qual Life Res. 2018;27(2):389-400.

\section{Publisher's Note}

Springer Nature remains neutral with regard to jurisdictional claims in published maps and institutional affiliations.

Ready to submit your research? Choose BMC and benefit from:

- fast, convenient online submission

- thorough peer review by experienced researchers in your field

- rapid publication on acceptance

- support for research data, including large and complex data types

- gold Open Access which fosters wider collaboration and increased citations

- maximum visibility for your research: over $100 \mathrm{M}$ website views per year

At BMC, research is always in progress.

Learn more biomedcentral.com/submissions 